\title{
Male Involvement in Prevention of Mother to Child Transmission (PMTCT) and Associated Factors in Ambo Town, Ethiopia
}

\author{
Eriste Nugusa Gamshe ((BSN, MSC/MRH) ${ }^{1}$ \\ Dereje Bayissa Demissie (BSN, MSC/MRH, Ass't Professor) ${ }^{1 *}$ \\ *Corresponding Author and Principal Investigator, \\ ${ }^{1}$ Saint Paul's Hospital Millennium Medical College
}

\begin{abstract}
Introduction: Globally, male partner involvement has been recognized as a priority focus area to be strengthened in PMTCT; as it decreases the risk of MTCT and HIV related deaths. It also has great contribution in ensuring PMTCT service uptake among mothers and in ensuring survival of infants born to HIV-positive mothers. But the male partners' involvement in PMTCT remains to be challenge in most low-middle income countries including Ethiopia and less is known about the reasons for the less or non-involvement of male partners in the service receipt. This study, therefore, was aimed at identifying factors associated with male partners' involvement in PMTCT. Methods: A community based cross-sectional study was employed among men whose wife had given birth to at least one child, whose age less than 2 years at the study period, in West Shoa zone Ambo town. A simple random sampling was used to get the total of 374 male participants. The returned questionnaires were checked for completeness, cleaned manually, coded and entered into EPI INFO 7.1.6 version and transferred to statistical Package for Social Sciences 23.0 for further analysis. Bivariate and multivariable logistic regressions analysis was used to identify factors associated with factors associated with male partners' involvement in PMTCT at AOR with $95 \%$ CI to controlled effects of possible confounders from final model. Results: Only less than half; $159(42.5 \%)$ with $95 \%$ CI; (37.7-47.6) of husbands got involved in the reception of HIV testing, counseling and caring services during ANC. Male partners undertake the birth preparedness and complication readiness $(A O R=$ 2.09, 95\% CI (1.13-3.9), male involved in ANC [AOR=30.02, 95\% CI (13.51-66.69)] and those had good knowledge on obstetric danger signs $[\mathrm{AOR}=2.987,(1.61-5.55)]$ more likely to get involved in PMTCT. Conclusion and recommendation: Male involvement in PMTCT program was found to be low in the study area. Male involved in ANC, participated in birth preparedness-complication readiness measures and having good knowledge on obstetrics danger signs were identified factors associated with male partner involvement in PMTCT. Finally, therefore, promotion of male partners' involvement in ANC as well as enhancing community based couples HIV testing and counseling are recommended as essential measures in fostering male partner involvement in PMTCT. Keywords: male partner involvement PMTCT
\end{abstract}

DOI: $10.7176 / \mathrm{JMPB} / 66-04$

Publication date:June 30th 2020

\section{Introduction}

Human Immune Virus infection is globally pandemic with worldwide high prevalence rate and remaining to be major barrier to community development. Globally, there appear to be huge differences in both the prevalence and incidences of HIV infection. At the end of 2014, the global estimate of total HIV-positive infections was 35 million people; nearly two-thirds (67\%) of which were in sub-Saharan Africa (1). However, the prevalence of HIV among pregnant women vary from region to region in sub-Sahara Africa; the prevalence is publicly significant. In Nigeria more than quarter of pregnant women $(26.4 \%)$ are HIV positive (2), while HIV prevalence among pregnant women in Kenya is $6.9 \%$ (3) and in Ethiopia it is 4.2\% (4); unlike the middle income countries such as Brazil where the prevalence among pregnant women is less than $1 \%(5)$

Despite widespread use of Antiretroviral Therapy (ART) by pregnant women living with HIV, the rate of MTCT of HIV in low-middle income countries including Ethiopia is still higher. In Ethiopia, among children born to HIV infected mothers $3.8 \%-18 \%$ are tested to be positive for HIV (6-9); where the prevalence of MTCT of HIV in India is $7.8 \%$ (10). The mother to child transmission (MTCT) of HIV in these regions is highly attributable to low partner involvement in PMTCT, poor ART adherence, low antenatal uptake, home delivery, mixed feeding during the first 6 months and extended breastfeeding to infants. However, in most of the cases male partners (men) play a key role in decision making for women access to health service including maternal health care (11).Male partner involvement in the perinatal care has significant effect on improving all perinatal care uptake, breastfeeding and even new born survival in Ethiopia, as well in other sub-Saharan Africa countries $(12,13)$. Whereas, only about $35 \%-50 \%$ of pregnant women, in Africa including Ethiopia, are accompanied to ANC by their partner $(14,15)$.

Therefore, a male partner involvement refers to full engagement of husband/spouse in the reception of health care such as HIV test and treatment; during maternal health care including the PMTCT service. Globally, male partner involvement has been recognized as a priority focus area to be strengthened in PMTCT (16). Similarly, the 
4-pronged WHO strategies for PMTCT promotes involvement of both partners; starting from the primary prevention throughout the care and treatment of HIV positive woman's family. Male partner involvement in PMTCT decreases the risk of mother to child transmission of HIV and HIV related deaths by 4 folds (17). It also has great contribution in enhancing the PMTCT service uptake among HIV positive mothers; as well in ensuring survival of infants born to HIV-positive mothers $(17,18)$. As well, HIV positive women whose male partner are involved in PMTCT are 3.51 times more likely to adherer to ART uptake, compared to those whose partners have no engagement in PMTCT (19). And so, none or less participation of male partners in PMTCT has impact on disease progression among the women, increases the risk of MTCT and generally positively influences the increment of HIV related challenges. While, in sub-Saharan Africa, where PMTCT and other HIV care services are provided in $>80 \%$ of health facilities, less attention is paid to strategies promoting the involvement of high risk groups including partners of HIV positive pregnant women, in the reception of preventive services including screenings at PMTCT units together with their wives or fiancée (20). And also, male partners screening in the context of PMTCT remains to be challenge in most low-middle income countries including Ethiopia, where in male partner involvement is as low as of $20.9 \%$ (16). In Ethiopia, where the proportion of men who have been tested for HIV is as low as of 15\% (21) especially in rural area, the male partner reception of HIV testing and counseling also remained to be low where only one fourth $(24.7 \%)$ of mothers have their partners screened for HIV at ANC (22). The male partner involvement in PMTCT is found to be less in low-middle income countries including Ethiopia where only about $40 \%-50 \%$ of women have their partners participate in PMTC $(23,24)$. However, great effort is put on strengthening the PMTCT services among HIV positive women in Ethiopia, less is known about the reason for the less or non-involvement of male partners in the service. So in general as the male partners involvement in PMTCT plays a key role in improving maternal perinatal and PMTCT services uptake and in reducing MTCT; it is worthy first to recognize reasons contributing to the none engagement of this group of a society. This study therefore was aimed at factors associated with male partners' involvement in PMTCT. With the purpose of giving a direction to work up on designing the necessary strategies which promote male partners involvement for the betterment of PMTCT outcome.

\section{Methods \\ Study settings and Design}

The study was conducted in Ambo town from January 01 to January 24, 2015 West Shoa zone Oromia regional state. During the study period, the zone has 5 hospitals, 88 health centers and 443 health posts with $93 \%$ of potential health service coverage. Ambo town has a total of three Keble's. A total of 776,754 individuals are living in Ambo Town (2007 CSA).From the total populations 28, 012 were males and 28,742 were females. One zonal hospital, two public health centers, one public $\mathrm{MCH}$ clinic and 15 private clinics provides health services for ambo town community.

All married/cohabiting males of household heads, whose wives had given birth to at least one child whose age less than 2 years of the study period and those who lived in Ambo Town for 6 months prior to data collection period. The sample size was computed to be 385 , by using single population proportion formula and by taking $\mathrm{p}$ value to be $60.4 \%$ (25) with a confidence level of $95 \%$ and marginal error of $5 \%$ by considering the $5 \%$ of none response rate. The houses holds with married male house heads whose wives had given birth within two years of the data collection period were identified and given codes Numbers) by a community survey. Sampling frame had been prepared by entering the number coded into SPSS version 20.0. Finally, the households were selected by using simple random sampling using computer generated household numbers.

Study design: A community based cross-sectional study design with quantitative data collection method was employed. Inclusion criteria were all married/cohabiting male of household head whose wife had given birth to at least one child in the last 2 years in the study area and living in Ambo Town for 6 months prior to data collection.

\section{Data management and data analysis}

The data collection too was adapted from the survey tools developed by JHPIEGO Maternal and Neonatal Health Program(26) and from reviews of different relevant literatures and variables identified to be measured. After undertaking pretest and modifying the questionnaire, a face to face interview had been undergone on the selected male participants, by trained data collectors. In this study male partner involvement was defined as the act of males, whereby they accompanied their female partners during ANC and received preventive services including HIV testing and counseling services in the context of PMTCT.

The returned questionnaires were checked for completeness, cleaned manually, coded and entered into EPI INFO 7.1.6 version and transferred to statistical Package for Social Sciences 23.0 for further analysis. Bivariate and multivariable logistic regressions analysis was used to identify factors associated with factors associated with male partners' involvement in PMTCT at AOR with 95\%CI to controlled effects of possible confounders from final model.

Ethical clearance was obtained from Ambo University College of Medicine and Health Sciences Ethical 
Committee. Letter of cooperation was written from Ambo town city administration, to all concerned bodies. The study participants also had provided verbal consent after being informed about the study objectives.

\section{Result}

Out of 374 husbands with wife in the reproductive age who had less than two years child were interviewed in ambo town with response rate of $97 \%(374 / 385)$.

\section{Socio demographic characteristics}

The mean age of study participant was $31.93 \pm 7.12$ years, with the age range of 17 to 60 years. Most of the respondents $319(85.3 \%$ ) belongs to Oromo ethnic group followed by Amhara, which was 43(11.5\%). Almost all $339(90.6 \%)$ of the participants attended formal education where, 165(44.1\%) were with diploma and above educational status. Occupationally; most $159(42.5 \%$ were private workers followed by government employees $138(36.9 \%)$ as shown in (Table 1$)$. As of the wives' age at their marriage; about quarter $92(24.6 \%)$ got married at early age before 18 years, with mean marital age of 21.32 (SD \pm 3.66 years) and about 2 in 3 wives of the participants [240(64.2\%)] were married by the age of 18-25years. Only 1 was 35 years old at marriage.

Table 1: Sociodemographic characteristics of 374 husbands with wife in the reproductive age who had less than two years child in Ambo Town, Oromia regional state, Ethiopia 2015

\begin{tabular}{|c|c|c|c|}
\hline Socio-demographic variables & Categories & Frequency(n) & $\begin{array}{l}\text { Percent } \\
(\%)\end{array}$ \\
\hline \multirow[t]{4}{*}{$\operatorname{Age}(n=374)$} & $\leq 20$ years & 13 & 3.50 \\
\hline & 20-30years & 253 & 67.6 \\
\hline & $\geq 30+$ years & 108 & 28.9 \\
\hline & Mean age of $31.93 \pm 7.12$ Std. Deviation & & \\
\hline \multirow[t]{3}{*}{ Ethnicity $(\mathrm{n}=374)$} & Oromo & 319 & 85.3 \\
\hline & Amhara & 43 & 11.5 \\
\hline & Others(Tigre, and Gurage) & 12 & 3.2 \\
\hline \multirow[t]{5}{*}{ Educational status $(n=374)$} & Illiterate & 18 & 4.8 \\
\hline & Read and write & 17 & 4.5 \\
\hline & Primary and secondary $(1-8)$ & 82 & 21.9 \\
\hline & High school and preparatory school(9-12) & 92 & 24.6 \\
\hline & College and above & 165 & 44.1 \\
\hline \multirow[t]{3}{*}{ Occupation $(\mathrm{n}=374)$} & Government & 138 & 36.9 \\
\hline & Merchant & 77 & 20.6 \\
\hline & Private & 159 & 42.5 \\
\hline \multirow{5}{*}{$\begin{array}{l}\text { Maternal first marriage age (n } \\
=374)\end{array}$} & $\leq 18$ years & 92 & 24.6 \\
\hline & 18.1-25years & 240 & 64.2 \\
\hline & $21.5-30$ & 33 & 8.8 \\
\hline & $30.1-35$ & 9 & 2.4 \\
\hline & $\begin{array}{l}\text { Mean } 1^{\text {st }} \text { mar age of } 21.32 \pm 3.66 \text { Std. } \\
\text { Deviation, ranging from } 12 \text { to } 35 \mathrm{yrs}\end{array}$ & & \\
\hline \multirow[t]{3}{*}{ Birth order/parity $(n=374)$} & 1year & 144 & 38.5 \\
\hline & 2-4years & 205 & 54.8 \\
\hline & $>4$ year & 25 & 6.7 \\
\hline
\end{tabular}

Participation and attitude on partner involvement in perinatal care, and awareness on danger signs

As of the attitude of male partners towards involvement in ANC, about three fourth; 276(73.8) had positive attitude to accompany wives/or female partner during ANC. whereas; only half 184(49.2\%) and $224(59.9 \%)$ respond they had participated in birth preparedness and complication readiness and antenatal care respectively. Similarly, slightly more than half $210(53.7 \%$ ) knew about obstetric danger signs as detailed in (Table 2).

Ethnic group, educational status and occupation of the male partner were the three sociodemographic characteristics identified to have strong association with ANC involvement of partners. According to this study being Amhara $[\mathrm{AOR}=0.355,95 \% \mathrm{CI}(0.170-0.741)]$ and Tigre $[\mathrm{AOR}=0.140,95 \% \mathrm{CI}(0.333-0.601)]$ ethnic group was less likely to be involved in ANC as compared to Oromo. 
Table 2: Participation and attitude on partner involvement in perinatal care, and awareness on danger signs; among husbands with reproductive age women who had children less than 2 years of age, Ambo Town, Oromia regional state, Ethiopia $2015(\mathrm{n}=374)$

\begin{tabular}{|c|c|c|c|c|}
\hline Variables & Category & Frequency(n) & $\begin{array}{l}\text { Percent } \\
(\%)\end{array}$ & $\begin{array}{l}95 \% \text { confidence } \\
\text { interval }\end{array}$ \\
\hline \multirow{3}{*}{$\begin{array}{l}\text { Attitude husbands should accompany their } \\
\text { wives to ANC: }\end{array}$} & & $\mathrm{n}=374$ & & \\
\hline & $\begin{array}{l}\text { Favorable/positive } \\
\text { attitude }\end{array}$ & 98 & 26.2 & $(21.7-30.7)$ \\
\hline & Negative & 276 & 73.8 & $(69.3-78.3)$ \\
\hline \multirow[t]{2}{*}{$\begin{array}{l}\text { Knowledge about danger signs in } \\
\text { pregnancy/delivery: }\end{array}$} & No & 173 & 46.3 & $(41.2-51.6)$ \\
\hline & yes & 210 & 53.7 & $(48.4-58.8)$ \\
\hline \multirow[t]{2}{*}{ Involvement during recent ANC: } & No & 150 & 40.1 & $(34.8-44.9)$ \\
\hline & Yes & 224 & 59.9 & $(55.1-65.2)$ \\
\hline \multirow{2}{*}{$\begin{array}{l}\text { Involvement in birth preparedness and } \\
\text { complication readiness }\end{array}$} & Not participated & 190 & 50.8 & $(44.1-54.3)$ \\
\hline & Participated & 184 & 49.2 & $(45.7-55.9)$ \\
\hline \multirow[t]{2}{*}{ Involved in PMTCT } & No & 215 & 57.5 & $(52.4-62.3)$ \\
\hline & Yes & 159 & 42.5 & $(37.7-47.6)$ \\
\hline
\end{tabular}

\section{Male partner involvement in PMTCT}

It was identified that only less than half; 159(42.5\%) with 95\% CI; (37.7-47.6) of husbands got involved in the reception of HIV testing, counseling and caring services; while their corresponding pregnant partners receive PMTC at ANC units of the health settings.

\section{Factors associated with male partner involvement in PMTCT}

In the bivariate analysis, the husband's or male partners educational and occupational status; their involvement in $\mathrm{ANC}$ and birth preparedness-complication readiness; their knowledge level about obstetric danger signs as well as their attitude towards the need of male partner involvement in ANC had significant association with male partners involvement in PMTCT during perinatal cares. The identified factors by multivariate logistic regression analysis were as follow:-

Male partners who undertake the birth preparedness and complication readiness measure before a hand of delivery were 2.09 times $(\mathrm{AOR}=2.09,95 \% \mathrm{CI}(1.13-3.9)$ more likely to had involved in PMTCT when compared to those who did not engage in the birth preparedness and complication readiness.

Male partner involvement in ANC had strong association with their participation in the uptake of HIV preventive and care services during PMTCT at perinatal care units. Where in, male partners who had accompanied their female partners during $\mathrm{ANC}$ were found to be 30 times [AOR=30.02, 95\% CI (13.51-66.69)] more likely to be involved in PMTCT compared to their counter parts. Having good understanding of obstetric dangers signs also found to favor male partner's participation in in the receipt of HIV preventive and caring services in the context of PMTCT. As shown in table 5; male partners who had good knowledge on pregnancy, labor and postnatal danger signs were 3 times $[\mathrm{AOR}=2.987,(1.61-5.55)]$ more likely to get involved in PMTCT. In addition to being associated with the PMTCT involvement of partners, these variables are interrelated where in one has significant association with other. On chi-square test the male partner involvement in ANC has strong association with their knowledge level on danger signs (chi-square $=20.919 ; \mathrm{P}=0.000$ ) and their participation in partner involvement in birth preparedness-complication readiness (chi-square $=32.957 ; \mathrm{P}=0.000$ ). 
Table 3: Factors associated with male partner involvement in PMTCT, by multivariate logistic regression analysis, in Ambo Town Oromia regional state, Ethiopia 2015

\begin{tabular}{|c|c|c|c|c|c|c|}
\hline \multirow[t]{2}{*}{ Variables } & \multirow[t]{2}{*}{ Category } & \multicolumn{2}{|c|}{$\begin{array}{l}\text { Male involvement in } \\
\text { PMTCT }(n=374)\end{array}$} & \multirow[t]{2}{*}{$\operatorname{COR}(95 \% \mathrm{CI})$} & \multirow[t]{2}{*}{ PV } & \multirow[t]{2}{*}{$\operatorname{AOR}(95 \% \mathrm{CI})$} \\
\hline & & Yes $(\%)$ & No $\%$ & & & \\
\hline \multirow{2}{*}{$\begin{array}{l}\text { Male partner } \\
\text { participation in } \\
\text { BPCR }\end{array}$} & $\begin{array}{l}\text { Didn't } \\
\text { participate }\end{array}$ & $46(12.3)$ & $138(36.9)$ & $1: 00$ & & $1: 00$ \\
\hline & Participated & $113(30.2)$ & $77(20.6)$ & $\begin{array}{l}4.403(2.830- \\
6.849)^{* * *}\end{array}$ & 0.020 & $\begin{array}{l}2.090(1.125- \\
3.881)^{*}\end{array}$ \\
\hline \multirow[t]{2}{*}{$\begin{array}{l}\text { Male involved } \\
\text { in antenatal care } \\
(\mathrm{ANC})\end{array}$} & $\begin{array}{l}\text { Didn't } \\
\text { accompany } \\
\text { during ANC }\end{array}$ & $8(2.1)$ & $142(38.0)$ & $1: 00$ & & $1: 00$ \\
\hline & $\begin{array}{l}\text { Accompanied } \\
\text { during ANC }\end{array}$ & $151(40.4)$ & $73(19.5)$ & $\begin{array}{l}36.716(17.084- \\
78.909)^{* * *}\end{array}$ & 0.000 & $\begin{array}{l}30.018(13.511- \\
66.694)^{* * *}\end{array}$ \\
\hline \multirow{2}{*}{$\begin{array}{l}\text { Knowledge on } \\
\text { obstetric danger } \\
\text { signs }\end{array}$} & Poor knowledge & $41(11.0)$ & $132(35.3)$ & $1: 00$ & & $1: 00$ \\
\hline & $\begin{array}{l}\text { Good } \\
\text { knowledge }\end{array}$ & $118(31.6)$ & $41(11.0)$ & $\begin{array}{l}4.577(2.921- \\
7.171)^{* * *}\end{array}$ & 0.001 & $\begin{array}{l}2.987(1.606- \\
5.554)^{* * *}\end{array}$ \\
\hline
\end{tabular}

Note: $* * * \mathrm{p}<0.001, * * \mathrm{p}<0.01, * \mathrm{P}<0.05$

\section{Discussion}

In this study it was revealed that only less than half $159(42.5 \%)$ [with 95\% CI; (37.7-47.6)] of husbands or male partners get involved in the reception of HIV testing, counseling and caring services in the context of PMTCT. This study finding is higher than the result observed in Kenya, in which the male partner involvement in PMTCT was found to be $22 \%(27)$. The dissimilarity may be because of sociodemographic difference between these two regions of Africa. It could also be associated with afraid of knowing one's HIV status with the intent of high chance of acquiring HIV infection among Kenyan male partners where MTCT rate is a bit higher(6.9\%)(3) than it is in Ethiopia in 2016 (4.2\%) (4). This justification can also be supported by a study conducted in Zimbabwe (28); which evidenced that being afraid of knowing one's HIV status is one of the major factors for which male partners failed to participate in PMTCT. As the rate of MTCT is higher in Kenya, it may also be justified with the fact that women who have known their HIV positive status are less likely to invite their partners both to perinatal and PMTCT services; as it was evidenced by a study conducted in Mekele (29). Similarly, despite better knowledge on PMTCT among male population in Amhara and Tigray regions of Ethiopia (21); in this study the magnitude of partner involvement in PMTCT is highest compared to the findings reported by studies in Gonder (Amhara region) 20.9\%(30) and Mekele (Tigray region) 20.1\% (29). This discrepancy could be associated with the likelihood of partners' involvement in ANC in relation to the ethnic group they belongs to. Because in this study, which was conducted in Ambo (Oromia region), it was evidenced that belonging to Amhara $[\mathrm{AOR}=0.355$, 95\% CI (0.170-0.741)] and Tigre [AOR $=0.140,95 \%$ CI (0.333-0.601)] ethnic group, lessen the likelihood of male partner involvement in ANC as compared to those belonging to Oromo tribe. Where, in other way the male partners' ANC involvement has strong association with their involvement in PMTCT. But finding in this study is lower than the result observed by a study conducted in South Africa; where the people may have better information regarding health care service and even there might be different strategies promoting male partner involvement in PMTCT.

Under binary logistic regression, in this study five variables including husbands' educational level, occupation, involvement in birth preparedness, involvement in ANC and their knowledge level on obstetric danger signs had association with partner involvement in PMTCT. Where, in multiple logistic regression the last three were determined to be factors associated with partner involvement in PMTCT. Male partners who participated in undertaking the birth preparedness and complication readiness measures were 2.09 times $(\mathrm{AOR}=2.09,95 \% \mathrm{CI}$ (1.13-3.9) more likely to be involved in PMTCT when compared to those who did not engage. Similarly, male partner involvement in ANC also was found to favor the male partners' involvement in PMTCT. Male partners who had ever accompanied their wives during ANC were found to be 30 times [AOR=30.02, 95\% CI (13.5166.69)] more likely to be involved in PMTCT compared to their counterparts. This can be justified with the fact that ANC is the first point of entry for the rest perinatal and other obstetric cares including PMTCT. So that the participants, which means a woman and/or her partner, would get the necessary information regarding all the perinatal care components, the PMTCT service and the neonatal health care too. And even they start to receive most of the cares including PMTCT on their first ANC visit. This had been realized by a systematic review/metaanalysis in developing countries and a cohort study in Zambia, where in both cases it was proven that male partner involvement during pregnancy had significant association with improved utilization of other maternal health services $(31,32)$. Additionally, a study in Kenya also supports this argument, as it had revealed that, partners who had get the chance of reading mother-child booklets during ANC, were about 3 times more likely to be involved in PMTCT and receive HIV testing/ counselling services (27). Male partner involvement in birth preparedness and 
complication readiness is also other factor increasing the likelihood of involvement in PMTCT by 2.09 folds. Together with others health issues, birth preparedness and complication readiness is counseled during ANC. Therefore, in this study too, male partners who would accompanied their wives during ANC might get counseling both on the birth preparedness-complication readiness and PMTCT simultaneously. On other hand, having information about PMTCT among male partners increases their involvement index in uptake of the service with their wives; as it had been evidenced by a study conducted in Gonder(30). Having good understanding of obstetric dangers signs was also found to favor male partner's participation in the receipt of HIV preventive and caring services in the context of PMTCT. Male partners who had good knowledge on pregnancy, labor and postnatal danger signs were 3 times $[\mathrm{AOR}=2.987,(1.61-5.55)]$ more likely to get involved in PMTCT. Partners good understanding of the obstetric danger signs might change their perceived severity of those problems and so could helped them to engage in to the supportive and preventive actions which ever the risk is, including the MTCT of HIV infection. In congruent with this idea, health belief model states that having knowledge about a disease and its severity is one of the reasons which enhances people's health care seeking behavior (33). These three variables, which were verified to be factors association with partner involvement in PMTCT, also are recognized to be interrelated among themselves. On chi-square tests, the male partner involvement in ANC had strong association with their knowledge level on danger signs (chi-square=20.919; $\mathrm{P}=0.000$ ) and their participation in birth preparedness-complication readiness measures (chi-square $=32.957 ; \mathrm{P}=0.000$ ). Finally therefore, it could also be for this reason that male partner's involvement in ANC, their good level of knowledge on obstetrics danger signs and their involvement in birth preparedness; all together were found to be factors associated with male partners' involvement in uptake of HIV preventive services in context of PMTCT.

\title{
Conclusion and recommendation
}

In this study, male partner involvement in PMTCT was found to be low, wherein only less than half of husbands receive HIV infection preventive and care service in the context of PMTCT. The three interrelated variables ANC, birth preparedness-complication readiness and knowledge on danger signs were identified to be factors associated with male partner involvement in PMTCT. Male partners who did participated in birth preparedness-complication interventions, those who had been accompanied their wives during ANC and those with good knowledge about obstetric danger signs were more likely to be involved in PMTCT compared to their counter parts. Additionally, the three variables were interrelated, where both the partner's knowledge level and engagement significantly were associated with the partners' involvement in ANC. Therefore, it was justified that partners who had accompanied their wives during pregnancy would get the necessary information on danger signs, birth preparednesscomplication readiness, PMTC and so could be involved in the receipt of HIV preventive services in the context of PMTCT.

Policy makers and health planers would be better to design programs and plans to increase mobilizing of the local community on creating the awareness about male involvement in Antenatal care and birth preparedness and complication readiness through formal/informal education by using the evidences by incorporating IEC/BCC materials which considering male involvement in Antenatal care and birth preparedness and complication readiness in the society.

It would be better to give great emphasis on planning to increases male involvement in Antenatal care and birth preparedness and complication readiness in Ethiopia.

Federal ministry of health would be better to give greater emphases to address and designing effective strategies that promote male partners involvement in ANC is essential in fostering male partner involvement in PMTCT.

Therefore, those factors associated with male partner involvement in PMTCT would be emphatically considered during PMTCT program development by police makers in collaboration with others responsible bodies in developing countries.

- Couple based HIV testing and counseling should be accommodated in community health service packages.

- No opportunity should be missed to address male partners; whenever they accompany their wives for perinatal cares services including ANC, delivery and postnatal care services

- Emphasis has to be given to obstetric danger signs, birth preparedness-complication readiness and PMTCT matters while counselling couples at ANC. Thereby the sensitivity to uptake of available preventive services such as PMTCT, increases as a risk minimization measures

\author{
Declaration Section \\ Abbreviations \\ ANC: ---------------Antenatal care \\ AIDS: --------------acquired immune deficiency syndromes \\ HIV ..............human immune virus \\ $\mathrm{BP} / \mathrm{CR} \ldots$...birth preparedness and complication readiness
}


JHPIEGO...John Hopkins Program for International Education in Gynecology and Obstetrics;

MDGs ...millennium development goals

MMR: ...........Maternal mortality ratio;

SBA:-...........skilled birth attendance

SSA.............Sub Saharan Africa

UNFPA:-.......United Nations Population Fund

WHO: ...........World Health Organization

\section{Ethical Consideration:-}

Ethical clearance letter was initially obtained from Ambo University College of Medicine and Health Sciences Ethical Committee. Then written consent was secured from Ambo town administration bodies to get permission. Telling that his/her participation in the study was very important, every client to be interviewed was informed that he/she has a full right to discontinue the interview.

\section{Competing interests}

The author(s) declare that they have no competing interests

\section{Authors' contributions}

Eriste Nugusa Gamshe and Dereje Bayissa Demissie conceptualized the study, designed the study instrument and conducted the data analysis and wrote the first draft and final draft of the manuscript.

ENG and DBD: Approved the research proposal with some revisions, participated in data analysis, revised subsequent drafts of the paper and involved in critical review of the manuscript. All authors read and approved the final manuscript.

\section{Acknowledgement}

We owe great gratitude to the Ambo University, College of medicine and health sciences, department of Nursing and midwifery for supporting and funding this research project.

Our thanks also go to West zone Health office and Ambo Town Office for good facilitation and all data collectors and supervisors that were involved in the data collection process

\section{Reference}

1. Challacombe S. Global oral inequalities in HIV infection. Oral diseases. 2016;22:35-41.

2. Okonko IO, Osadebe AU, Onianwa O, Okereke S. Prevalence of HIV in a Cohort of Pregnant Women Attending a Tertiary Hospital in Ibadan, Nigeria. Immunology and Infectious Diseases. 2019;7(1):7-12.

3.Ndege S, Washington S, Kaaria A, Prudhomme-O'Meara W, Were E, Nyambura M, et al. HIV prevalence and antenatal care attendance among pregnant women in a large home-based HIV counseling and testing program in Western Kenya. PloS one. 2016;11(1):e0144618.

4.Woldesonbet Z. Hepatitis B and Human immunodeficiency virus co-infection among pregnant women in resource limited high endemic setting, Addis Ababa, Ethiopia: Implications for current and emerging prevention and control measures. International Journal of Infectious Diseases. 2016;45:204.

5. Domingues RMSM, Szwarcwald CL, Souza PRB, do Carmo Leal M. Prenatal testing and prevalence of HIV infection during pregnancy: data from the "Birth in Brazil" study, a national hospital-based study. BMC infectious diseases. 2015;15(1):100.

6. Beyene GA, Dadi LS, Mogas SB. Determinants of HIV infection among children born to mothers on prevention of mother to child transmission program of HIV in Addis Ababa, Ethiopia: a case control study. BMC Infectious Diseases. 2018;18(1):N.PAG-N.PAG.

7. Kassa GM. Mother-to-child transmission of HIV infection and its associated factors in Ethiopia: a systematic review and meta-analysis. BMC infectious diseases. 2018;18(1):216.

8. Yitayew YA, Bekele DM, Demissie BW, Menji ZA. Mother to Child Transmission of HIV and Associated Factors Among HIV Exposed Infants at Public Health Facilities, Dessie Town, Ethiopia. HIV/AIDS (Auckland, NZ). 2019;11:343.

9. Wudineh F, Damtew B. Mother-to-child transmission of HIV infection and its determinants among exposed infants on care and follow-up in Dire Dawa City, Eastern Ethiopia. AIDS research and treatment. 2016;2016.

10. Potty RS, Sinha A, Sethumadhavan R, Isac S, Washington R. Incidence, prevalence and associated factors of mother-to-child transmission of HIV, among children exposed to maternal HIV, in Belgaum district, Karnataka, India. BMC public health. 2019;19(1):386.

11.Demissie DB, Bulto GA, Terfassa TG. Involvement of male in antenatal care, birth preparedness and complication readinessand associated factors in Ambo town, Ethiopia. Journal of Health, Medicine and Nursing. 2016;27(5):14-23. 
12. Suandi D, Williams P, Bhattacharya S. Does involving male partners in antenatal care improve healthcare utilisation? Systematic review and meta-analysis of the published literature from low-and middle-income countries. International health. 2019.

13. Aguiar C, Jennings L. Impact of male partner antenatal accompaniment on perinatal health outcomes in developing countries: a systematic literature review. Maternal and child health journal. 2015;19(9):2012-9.

14. Kabanga E, Chibwae A, Basinda N, Morona D. Prevalence of male partners involvement in antenatal care visits-in Kyela district, Mbeya. BMC pregnancy and childbirth. 2019;19(1):1-6.

15. Mohammed BH, Johnston JM, Vackova D, Hassen SM, Yi H. The role of male partner in utilization of maternal health care services in Ethiopia: a community-based couple study. BMC pregnancy and childbirth. 2019;19(1):28.

16. Amano A, Musa A. Male involvement in PMTCT and associated factors among men whom their wives had ANC visit 12 months prior to the study in Gondar town, North west Ethiopia, December, 2014. Pan African Medical Journal. 2016;24:1-8.

17. Aluisio AR, Bosire R, Betz B, Gatuguta A, Kiarie JN, Nduati R, et al. Male partner participation in antenatal clinic services is associated with improved HIV-free survival among infants in Nairobi, Kenya: a prospective cohort study. Journal of acquired immune deficiency syndromes (1999). 2016;73(2):169.

18. Osoti AO, John-Stewart G, Kiarie JN, Barbra R, Kinuthia J, Krakowiak D, et al. Home-based HIV testing for men preferred over clinic-based testing by pregnant women and their male partners, a nested cross-sectional study. BMC infectious diseases. 2015;15(1):298.

19. Zacharius KM, Basinda N, Marwa K, Mtui EH, Kalolo A, Kapesa A. Low adherence to Option B+ antiretroviral therapy among pregnant women and lactating mothers in eastern Tanzania. PloS one. 2019;14(2):e0212587.

20. Church K, Machiyama K, Todd J, Njamwea B, Mwangome M, Hosegood V, et al. Identifying gaps in HIV service delivery across the diagnosis-to-treatment cascade: findings from health facility surveys in six subSaharan countries. Journal of the International AIDS Society. 2017;20(1):21188.

21. Central Statstical Agency E. Ethiopia Demographic and Health Survey 2016: Key indicators report. 2016.

22. Elias M, Mmbaga EJ, Mohamed AA, Kishimba RS. Male partner involvement in the prevention of mother to child transmission of HIV infection in Mwanza Region, Tanzania. The Pan African Medical Journal. $2017 ; 27$.

23. Zenebe A, Gebeyehu A, Derseh L, Ahmed KY. Male Partner's Involvement in HIV Counselling and Testing and Associated Factors among Partners of Pregnant Women in Gondar Town, Northwest Ethiopia. Journal of Pregnancy. 2016:1-6.

24.Tilahun M, Mohamed S. Male Partners' Involvement in the Prevention of Mother-to-Child Transmission of HIV and Associated Factors in Arba Minch Town and Arba Minch Zuria Woreda, Southern Ethiopia. BioMed Research International. 2015;2015:1-6.

25. Gebrehiwot H, Gebregziabher W, Gidey G. Assessment of Husbands' Participation on Birth Preparedness and Complication Readiness in Enderta Woreda, Tigray Region, Ethiopia, 2012. J Women's Health Care. 2013;3(140):2167-420.

26. JHPIEGO. Maternal and neonatal health. Monitoring birth preparedness and complication readiness tools and indicators for maternal and newborn health. Johns Hopkins, Bloomberg school of Public. Health, Center for communication programs, Family Care International; 2004. Available at: http://pdf.dec.org/pdf docs/PNADA619.pdf.; Accessed November 2013).

27. Oyugi E, Gura Z, Boru W, Githuku J, Onyango D, Otieno W, et al. Male partner involvement in efforts to eliminate mother-to-child transmission of HIV in Kisumu County, Western Kenya, 2015. The Pan African Medical Journal. 2017;28(Suppl 1).

28. Makoni A, Chemhuru M, Chimbetete C, Gombe N, Bangure D, Tshimanga M. Factors associated with male involvement in the prevention of mother to child transmission of HIV, Midlands Province, Zimbabwe, 2015a case control study. BMC public health. 2016;16(1):331.

29. Haile F, Brhan Y. Male partner involvements in PMTCT: a cross sectional study, Mekelle, Northern Ethiopia. BMC pregnancy and childbirth. 2014;14(1):65.

30. Amano A, Musa A. Male involvement in PMTCT and associated factors among men whom their wives had ANC visit 12 months prior to the study in Gondar town, North west Ethiopia, December, 2014. Pan African Medical Journal. 2016;24(1).

31. Yargawa J, Leonardi-Bee J. Male involvement and maternal health outcomes: systematic review and metaanalysis. J Epidemiol Community Health. 2015;69(6):604-12.

32. Kashitala J, Nyambe N, Mwalo S, Musamba J, Chishinga N, Kasonde P, et al. Is male involvement in ANC and PMTCT associated with increased facility-based obstetric delivery in pregnant women? African Journal of Reproductive Health. 2015;19(2):116-23.

33. Champion VL, Skinner CS. The health belief model. Health behavior and health education: Theory, research, and practice. 2008;4:45-65. 